\title{
Developing Sustainable Flood Risk Management Framework for Kebbi State, Nigeria
}

\author{
Abdullahi, Abubakar Sadiq \\ Geology Department, Faculty of Science, \\ Federal University Birnin Kebbi, Nigeria \\ Bakari, Ali \\ Geology Department, Faculty of Earth and Environmental Sciences, \\ Bayero University Kano, Nigeria
}

Doi:10.19044/esj.2020.v16n23p233 URL:http://dx.doi.org/10.19044/esj.2020.v16n23p233

\begin{abstract}
The objective of this study is to develop a sustainable flood risk management framework that can be applicable in Kebbi state. Relevant institutional stakeholders (public officials), households and community leaders were engaged via interviewees, focus group discussions and household surveys respectively in developing the framework. Results show that rainwater accounts for about $62 \%$ of the total source of water responsible for flooding in the study area, while River water and Groundwater constitute $33 \%$ and $3.3 \%$ respectively. Majority $(59 \%)$ of the stakeholders engaged disclose that flooding in their areas have had high impact on their means of livelihood. Furthermore, majority of the respondents confirm that they were affected by effects of with short to medium term recovery, while about $21.5 \%$ of the respondents believe that the damage caused is only recoverable over long term period. Stakeholders opted for the integrated approach that combines both structural and non-structural solutions and the enforcement of stringent legislations as well as strict compliance to building codes as the best strategies for addressing flooding in the study area. A set of recommendations to be applicable in the study area are outlined and the outcome of the paper will be useful to flood managers, policy and decision makers as well as other relevant stakeholders in the flood management domain in implementing sustainable flood risk management strategy.
\end{abstract}

Keywords: Developing, Sustainable, Flood Risk, Management

\section{Introduction}

Flooding occurs most commonly from heavy rainfall when natural watercourses lack the capacity to convey excess water. It can also result from 
other phenomena, particularly in coastal areas, by a storm surge associated with a tropical cyclone, a tsunami or a high tide (Vaze et al., 2013; UNISDR, 2019). They are a common natural disaster that is affecting both the developing and developed countries of the world. Therefore, understanding, assessing and predicting flood events and their impacts are important aspects of developing mitigation strategies that reduces economic losses (UNISDR, 2019). Also, floods have the tendency to cause severe consequences to the natural, modified and human systems in many parts of the world. These hazards vary in magnitude and intensity in time and space (Merz et al., 2010). Under certain conditions and influenced by triggering factors, they may cause loss of life, destroy infrastructures and properties, impede economic and social activities and cause destruction of cultural heritage monuments and the environment (Dutta et al., 2006).

According to the World Bank (2017) between 1980 and 2017, floods led to economic damages exceeding US\$1.6 trillion globally, and more than 225,000 people lost their lives. Compounded by rapid urbanisation and climate change, these losses are likely to increase throughout the 21 st century. Globally, climate change and urban development have radically increased the frequency and the severity of flooding events. This has generated a lot of interest within the scientific community in conducting more accurate studies regarding flooding in urban areas.

In Nigeria floods have affected millions of people and caused fiscal losses amounting to billions of US dollars (World Bank, 2017). These hazards were generally linked to poor urban planning and climate change especially in increased frequency and intensity of rainfall. The major negative impacts of floods in Nigeria include deaths, physical injuries, widespread infection and vector-borne diseases, social disorders, homelessness, food insecurity, economic losses (mainly through destruction of farmlands, social and urban infrastructure) and economic disruption (interruption in telecommunication and power supply(Obi and Ubani, 2014; Oladokun and Proverbs, 2016; Nkwunonwo, 2016).

Different authors have carried out studies (e.g. Sada, 1988; Nelson, 2001; Samuel et al., 2015; Nkeki et al., 2013; Agbonkhese et al, 2014) that show increasing level of risk due to flooding in the country. Flood risks are a hurdle to the development of many African countries including Nigeria that see their gross domestic product and investments impaired by the impact of such Flood hazards (World Bank, 2017). During the past few decades, floods have caused the loss of hundreds of thousands of human lives with damages and property losses of millions of Dollars in Nigeria. Numerous devastating flood disasters have been reported by previous studies (Adedeji et al., 2012; Olajuyigbe et al., 2012; Kolawole et al., 2011) in the country. According to the National Emergency Management Agency (2012), the 2012 Floods are the 
most destructive in the recent history of Nigeria. It affected about 30 out of the 36 States of Nigeria, 7 million peopled were affected in these States, a total of 597, 476 houses were destroyed, 2.3 million people were displaced and 363 deaths were reported with large track of farmland and other means of livelihood destroyed.

Also, the UN Post Disaster Needs Assessment conducted from 2014 to 2016 estimated the total value of infrastructure, physical and durable assets destroyed in Nigeria at \$9.6bn (World Bank, 2017). The total value of losses across all sectors of the economy was estimated at $\$ 7.3 \mathrm{bn}$. The combined value of these damages and losses was put at US\$16.9bn. Furthermore, the severe effects of flooding in the country are linked to poverty, low levels of infrastructural development and inadequacy of knowledge, low levels of coping and adaptation capacities, lack of insurance cover, weak institutions and other problems associated with emergency response and early warning communications (Kolawole, 2011; UNISDR, 2019; Most et al., 2017).

Presently, in Nigeria, the technical capacities of the various tiers of government (federal, state and local), and their relevant agencies responsible for managing flood related issues and the relevant stakeholders involved in managing flood disaster are low (Hewitt 1999; Pradhan, 2009; Bello and David, 2014). Other problems include the unavailability of relevant scientific data required for developing sustainable flood risk management framework in the country. Likewise, there is lack of coherent government policy to radically address the challenges of flooding in the country (Wang, 1999; Hewitt, 1999; Apel et al., 2006; Gallegos et al., 2009; UNISDR, 2019)

In Nigeria, flooding has worsened recently due to a number of possible factors including rapid population growth, poor and unplanned urbanisation, and climate change conditions. Additionally, the lack of reliable data on past flooding events and future flooding forecasts is a major setback towards tackling flooding in Nigeria and this needs to be addressed urgently. Also, it is obvious that the success of flood risk reduction depends largely on knowledge-based decision support tool, robust institutional framework and flood risks communication; but these factors are currently inadequate in Nigeria.

Consequently, in Kebbi State, precipitation often falls as rain during raining season leading to changes in Rima river flows primarily due changes in the volume of water (Bates et al, 2018). The river often overruns its bank and results into recurrent flooding in the metropolis and its environs (Fig 1). Movements of both vehicles and humans become generally impeded; offices, schools, residential houses and business activities become generally affected by the flood (Kolawole, 2011). Birnin-Kebbi metropolis often experienced increase in precipitation with its attendant Rima river flood annually. 
Continued global greenhouse gas emission at, or above the current rates will cause further warming and induce many changes on the local climate system. Therefore, it is very likely that hot extremes and heat waves will continue to become more frequent, thereby exposing most parts of Kebbi State including Birnin-Kebbi metropolis to such extreme condition (Figure $1 \mathrm{a}, \mathrm{b}$ and $\mathrm{c}$ ).

Lastly, efforts to tackle flood risks and hazards by way of engaging the relevant stakeholders in addressing the situation are limited in Nigeria. Much of what is known in the literature regarding flooding in the country is deficient on remedies. The Sendai Framework for Disaster Risk Reduction provides the framework for the engagement of relevant stakeholders in developing local mitigation strategies in the context of sustainable development and poverty eradication (UN, 2019).

Therefore, the objectives of the study is to develop a suitable flood risk management framework by taking into account the responses of all the relevant stakeholders that are involved in the management of flood risks in the country. This will be important towards mitigating the negative effects of flooding in the country and it will be vital in enhancing the capacities of the citizenry and other relevant institutions. If fully developed, the framework can be applicable in Kebbi State and the entire country at large. This will aid the attainment of the Sendai Framework for Disaster Risk Reduction in the country.

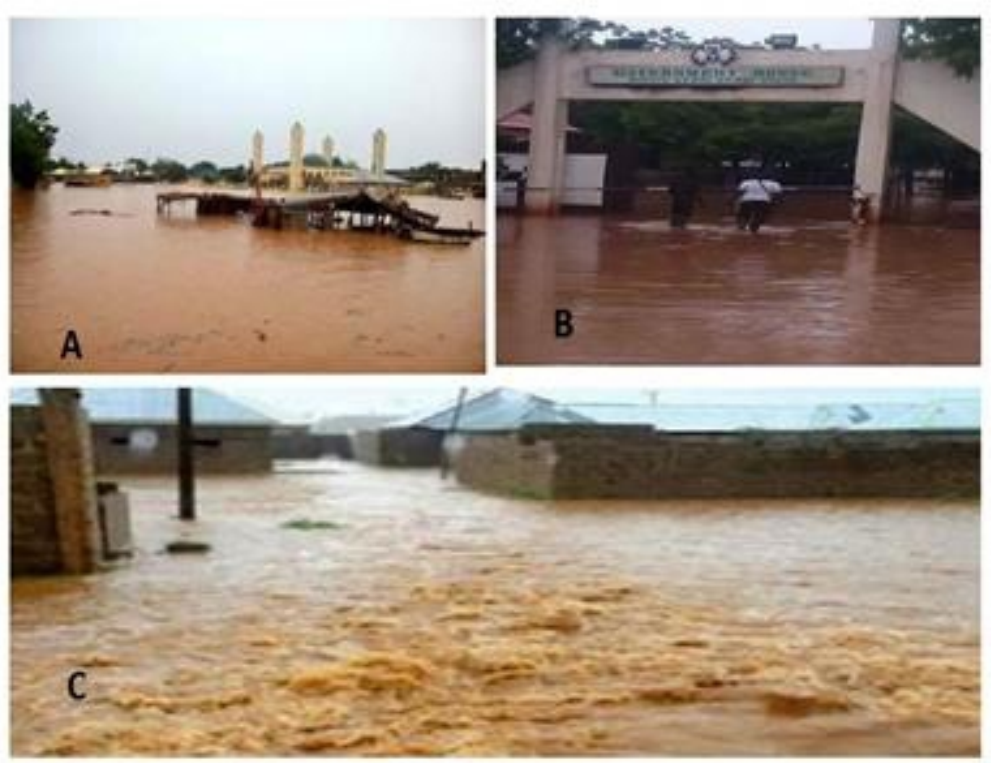

Figure 1: (a) extreme flooding in Rafin Atiku area (B) flooded Gate of Government House Birnin Kebbi (c) flooding in Badariya area of Birnin-Kebbi 


\section{Description of study area}

Birnin Kebbi is the capital city of Kebbi State located on latitude $10^{\circ} \mathrm{N}$ to $13^{\circ} \mathrm{N}$, and longitude $3^{\circ} \mathrm{E}$ to $6^{\circ} \mathrm{E}$ in the North-western part of Nigeria (Fig 2). Kebbi state is sharing its Northern and Western boundaries with Niger Republic; it is bounded by Sokoto state to the East, while Niger state is located at its Southern boundary. The 2006 census figure shows that Kebbi State has a total population of 2,596,589; with male population being higher than that of females by 58,033 (Chorko, 2003). The study area is located in the semiarid zone of north-western Nigeria; Birnin Kebbi enjoys the warm tropical climatic condition of Western Africa. Most parts of the state fall within the Sudan Savannah vegetation zone.

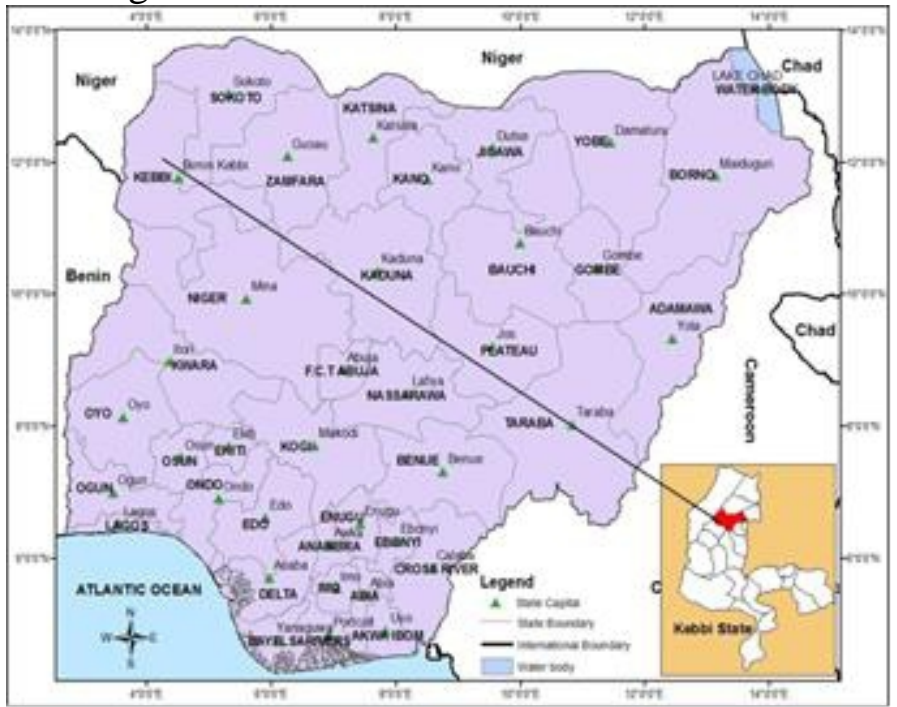

Fig 2: Map of Nigeria showing Kebbi state (After Kaoje, 2014)

The study area has three distinct seasons: a long hot dry season from April to May. Day time temperatures are in the range of 36 to $40^{\circ} \mathrm{C}$ and night time temperatures fall to 11 to $18^{\circ} \mathrm{C}$. This is followed by a short rainy season from June to September with a daily minimum temperature of $24^{\circ} \mathrm{C}$ and a maximum of $34^{\circ} \mathrm{C}$ with relative humidity of 40 to $65 \%$ and annual rainfall from 560 to $600 \mathrm{~mm}$. Finally, the cold (Harmattan) season runs from October to March when temperatures fall to about $20^{\circ} \mathrm{C}$ and a dry dusty wind blows from the Sahara desert (Bakari, 2014).

\section{Methodology}

This study employed both qualitative and quantitative Methods of data collection and analysis. The qualitative strand involves the synthesis of secondary data from relevant literatures and government reports and other grey literatures. While the quantitative method involved a 3 days 
reconnaissance survey across the study area, and 1 month (August to September 2017) quantitative data collection such as geodetic height measurement of datum to determine the risks of flooding in the study area and household surveys to enable the collection of primary data that will aid the incorporation of household's opinion in developing the sustainable framework for mitigating flooding in the study area.

A stakeholder analysis was carried out from the beginning of the study in August 2017 to identify the various stakeholders that will address the current, emerging, and future problems of flooding in the study area. In this respect, a total of 3 different stakeholder groups consisting of 14 individual groups and organisations; which consists of Government ministries/agencies, local residents and community representatives were identified (Table 1). The government agencies identified by the stakeholder analysis include Ministries of Land, Housing and Environment. Also, Kebbi Urban Development Agency (KUDA) was included.

Also, the reason for selecting these stakeholder groups is because they are the ones directly affected by the problems of flooding, and are capable of providing lasting solution in the study area. The representatives of the various stakeholder groups were engaged via interviews and focus group discussions.

Table 1: Summary of the various stakeholder groups in the study area

\begin{tabular}{ll}
\hline Organisation type & Number of groups \\
\hline Government ministries/ agencies & 4 \\
Local residents & 5 \\
Community representatives & 5 \\
\hline
\end{tabular}

\section{Data collection}

A total of 1500 household/community questionnaires were distributed to local residents and individuals across five (5) flood prone areas namely; Rafin-Atiku, Badariya, Bayan-kara, Aliero quarters and Makerar Gwandu areas of Birnin Kebbi metropolis. The households were selected via stratified random sampling methodology. About 300 household questionnaires were administered to the various households of the 5 affected areas between September 2017 and February 2018 in Birnin Kebbi metropolis; a response rate of $86.6 \%$ was achieved. Prior to this, research assistants with good education were recruited from within the local communities to help administer and interpret the questions to the households. The research assistants were trained to ask the questions (interpret from local language to English) properly and to help in filling out the questionnaires for the households with least education. Methods used in identifying the survey participants were also clarified to them. In addition, gender sensitive steps were taken to ensure representation of both males and females in the survey. 


\section{Result and Discussions}

Results obtained from both the interviews and household questionnaires show that $83.7 \%(n=1300)$ of the respondents are males while the remaining $16.3 \%(n=1300)$ are females. In general, about $78.7 \%$ of the inhabitants of the five areas surveyed confirm that they have experienced flooding in their respective domains.

The result also reveal that about $62 \%$ of the household respondents confirm that rainwater is responsible for flooding in the affected areas while River water and Groundwater constitute $33 \%$ and $3.3 \%$ respectively. Flooding in the Northern part of the country is as a result of precipitation (Ologunorisa, 2004; Ojigi et al., 2013). Heavy rainfall coupled with uncontrolled anthropogenic activities and poor drainage infrastructure is the causative factor of flooding in most Nigerian cities and this has left hundreds of people distressed and homeless (Aderogba et al., 2012; Ogwuche and Abah, 2014).

Flooding in Nigeria are either fluvial (resulting from rivers overtopping their natural and manmade defences), coastal (affecting mainly the coastal areas) or pluvial (flash, arriving unannounced following a heavy storm) in nature and have been a major cause of concern for rural areas and cities within the country (Bashir et al. 2012; Douglas et al. 2008).

Result show that majority $(81 \%)$ of the institutional stakeholders are knowledgeable about flooding issues while the respondents lacked adequate knowledge about it. Different authors (e.g. Obi and Ubani, 2016; Nkwunonwo, 2016) observed that illiteracy and ignorance are some of the major impediments to achieving sustainable flood risk management in Nigeria. Despite their limited knowledge about flooding, some of the households that lived in the study area for a long period attribute the flooding in their areas of abode to the annual flash floods while others make reference to the occasional release and overflow of Goronyo Dam (River Rima) from the neighbouring Sokoto State.

The findings of the study further show that about $40 \%$ of the respondents have lived in the study area for more than 20years. Also, about $14 \%$ of the respondents have lived in the area for a period ranging from 11-15 years. Likewise, majority of the interviewees confirm that the study area is likely to experience flooding in the future. Contrastingly, only about $22.3 \%$ of the respondents are optimistic that the problem of flooding will be addressed by the present administration in the state. This view can be attributed to the most recent construction of drainages and roads embarked upon by the state government.

As often associated with flood disasters, loss of livelihood commonly takes its toll on the people in the affected areas as resident's counts their losses, flooding over the years have resulted in severe damage of properties and local businesses. Some of the respondents $(38 \%)$ disclose that there has been no 
significant impact on their means of livelihood. Majority (59\%) of the households engaged confirm that there has been a high impact on their means of livelihood as shops and farmlands were washed away by the heavy downpour especially in Bayan kara and Badariya Areas respectively. Likewise, about $28 \%$ of the respondents reveal that their livelihood were affected moderately as the overflow of flood water was only for short period, hence, the damage to livelihood was only minimal, this is the case for respondents from Rafin Atiku and Aliero quarters of Birnin-Kebbi Metropolis.

Flooding causes severe environmental and ecological damages through ecosystem and biodiversity losses. In this respect, a total of $8.4 \%$ of the respondents lamented that their habitat and farmlands have been damaged only minimally while $43 \%$ believed that both the environment and their resources have been damaged with short term recovery. Also, about $21.5 \%$ of the respondents believe that the damage caused by flood water is only recoverable over a long term. Majority (26.9\%) of the respondent were of the view that the damage caused is beyond recovery (Table 2). Economic losses and environmental disturbance due to flooding in Nigeria have been outlined by Ologunorisa (2005) and Fadairo and Ganiyu (2010). The economic and environmental losses in Nigeria as estimated by the UN (2016) are about \$9.6bn (World Bank, 2017). The total value of losses across all sectors of the economy was estimated at $\$ 7.3 \mathrm{bn}$. The combined value of these damages and losses was put at US\$16.9bn.

Table 2: Environmental Impact in the study area

\begin{tabular}{lcc}
\hline \multicolumn{1}{c}{ Impact } & Frequency & Percentage \\
\hline Little or no environmental damage & 110 & 8.4 \\
Resources damaged with short term recovery & 560 & 43 \\
Resources damaged with long term recovery & 280 & 21.6 \\
Resources destroyed beyond recovery & 350 & 27 \\
\hline Total & 1300 & 100 \\
\hline
\end{tabular}

Source: Author's Field Survey 2018

Similarly, the dominant land use in the study area as obtained from the questionnaire outcomes illustrate that Agricultural area constitute about $62 \%$, Residential area constitute about $23 \%$ while Industrial area is about $11 \%$. Agricultural land constitutes the vast majority of the area. According to some government officials from the Kebbi Urban Development Board, the exact proportions of the different land use types are very difficult to obtain. Rather it can only be estimated; the officials further disclosed that they are constrained by the non-availability of an updated master plan of the metropolis. They believed that issues related to flooding can be addressed with the aid of the master plan.

Additionally, the result from the interview of institutional (ministries/agencies) stakeholders and the focus group discussions of 
community leaders show that most government officials are aware of issues attributed to climate change conditions and their negative effects on flooding. Majority of the community leaders engaged in the focus group discussions are unaware of climate change and its negative effects. Also, over $70 \%$ of the households affirm that they are unaware of climate change. Flooding in Nigeria is generally linked to climate change and it is likely to increase in the future (Adeloye \& Rustum, 2011; Action Aid 2006).

Low levels of education and unawareness of contemporary global challenges attributed to extreme weather conditions by the citizenry are major impediments to achieving a sustainable flood risks management in Nigeria (Adedeji et al., 2013; Adegbola and Jolayemi, 2013; Samuel et al., 2015; UNISDR, 2019). In this respect, educating the citizenry on topical issues related to climate change conditions and their impacts on flooding as well as the review of environmental curriculum in schools will be vital in providing awareness to the general public.

Furthermore, both institutional stakeholders (government officials) and the citizenry (household respondents) were asked to choose the best strategy for addressing flood risks from the list of options presented to them on how flooding risks can be mitigated in their areas. In this respect, majority of the institutional stakeholders believe that the combination of engineering solutions and the enforcement of stringent legislations as well as strict compliance to building codes is the best way of addressing flooding issues in the metropolis. In this respect, Nkwunonwo (2016) recommends that integrated approaches that combines both structural and non-structural solutions is the way forward in addressing urban flooding.

Similarly, majority $(50.8 \%)$ of the respondents believe that engineered solutions are the best way of addressing flooding problems. About $24 \%$ confirm that ensuring strict compliance of building codes will be the best strategy for addressing flooding problems in their respective areas. Similarly, about $17.2 \%$ believe that participation of the citizenry in planning will be the best strategy. Sustainable flood risk management integrates both structural and non-structural measures to achieve the key elements of risk management (UN, 2019; Most et al., 2017). 
Table 5: summary of the elevation of the different areas of the study area

\begin{tabular}{llll}
\hline $\begin{array}{l}\text { Location } \\
\text { Name }\end{array}$ & Points & \multicolumn{1}{c}{ Coordinates } & Altitude (m) \\
\hline Badariya & 1 & $\mathrm{~N} 12^{\circ} 26^{\prime} 53.58^{\prime \prime}, \mathrm{E} 4^{0} 12^{\prime} 44.47^{\prime \prime}$ & 241 \\
& 2 & $\mathrm{~N} 12^{\circ} 26^{\prime} 42^{\prime \prime}, \mathrm{E} 4^{\circ} 103^{\prime} 37^{\prime \prime}$ & 244 \\
& 3 & $\mathrm{~N} 12^{\circ} 26^{\prime} 48^{\prime \prime}, \mathrm{E} 4^{\circ} 11^{\prime} 7^{\prime \prime}$ & 239 \\
\hline Rafin & 1 & $\mathrm{~N} 12^{\circ} 26^{\prime} 40^{\prime \prime}, \mathrm{E} 4^{\circ} 11^{\prime} 20^{\prime \prime}$ & 240 \\
Atiku & 2 & $\mathrm{~N} 12^{\circ} 26^{\prime} 51^{\prime \prime}, \mathrm{E} 4^{\circ} 11^{\prime} 44^{\prime \prime}$ & 237 \\
\hline Makerar & 1 & $\mathrm{~N} 12^{\circ} 27^{\prime} 3^{\prime \prime}, \mathrm{E} 4^{\circ} 111^{\prime} 30^{\prime \prime}$ & 238 \\
Gwandu & 2 & $\mathrm{~N} 12^{\circ} 27^{\prime} 14^{\prime \prime}, \mathrm{E} 4^{\circ} 11^{\prime} 19^{\prime \prime}$ & 234 \\
\hline Bayan & 1 & $\mathrm{~N} 12^{\circ} 27^{\prime} 25^{\prime \prime}, \mathrm{E} 4^{\circ} 12^{\prime} 29^{\prime \prime}$ & 236 \\
Kara & 2 & $\mathrm{~N} 12^{\circ} 27^{\prime} 23^{\prime \prime}, \mathrm{E} 4^{\circ} 12^{\prime} 44^{\prime \prime}$ & 232 \\
& 3 & $\mathrm{~N} 12^{\circ} 27^{\prime} 14^{\prime \prime}, \mathrm{E} 4^{\circ} 12^{\prime} 51^{\prime \prime}$ & 228 \\
\hline Aliero & 4 & $\mathrm{~N} 12^{\circ} 27^{\prime} 12^{\prime \prime}, \mathrm{E} 4^{\circ} 13^{\prime} 1 "$ & 225 \\
Quarters & 1 & $\mathrm{~N} 12^{\circ} 27^{\prime} 51^{\prime \prime}, \mathrm{E} 4^{\circ} 15^{\prime} 31^{\prime \prime}$ & 222 \\
& 2 & $\mathrm{~N} 12^{\circ} 28^{\prime} 6^{\prime \prime}, \mathrm{E} 4^{\circ} 14^{\prime} 30^{\prime \prime}$ & \\
\hline
\end{tabular}

Lastly, the result of the geodetic elevations measurement obtained from the field (Table 5) in characterising the vulnerability of the different areas to the effects of flooding, show that the study area lays between 222 and 244 $\mathrm{m}$ above sea level. The highest point is in Badariya area which lay between 239-244 $\mathrm{m}$ and the lowest point is at Aliero quarters which ranged between 220-225 $\mathrm{m}$ above sea level. The geodetic datum difference in the whole of the study area is $22 \mathrm{~m}$. Taking, this into consideration, Aliero quarters is the most likely area prone to flooding; this is due its low lying position and the runoffs from the surrounding higher elevation areas are moving towards the area. This makes the area inundated by water which makes it more susceptible to flooding in comparison with other adjacent areas.

\section{Conclusion}

Critical issues relating to flooding risks in Birnin Kebbi metropolis have been outlined with a view to developing a reliable and sustainable flood risk management framework by the relevant stakeholders in Kebbi state. The effects of flooding according findings of this study has been largely attributed to many factors amongst which are climate change, poor drainage system, limited knowledge on issues related to flooding by the citizenry, weak legislations and their enforcement, poor waste disposal, indiscriminate building of structures along flood plains and lack of policy guidelines to streamline and enforce building codes. Thus despite the relatively high level of flood perception in the study area, government and individual's responses to flooding were inadequate. Therefore, the following recommendations will 
help provide solution and mitigate the negative effects of flooding in the study area;

a) Enhancement of the adaptive capacities of the citizenry through education and awareness creation and the provision of structural and non-structural solutions in curbing the risk of flooding in the study area.

b) Adequate legislations with regards to urban development need to be developed by the state legislators and enforced by the relevant authorities in addressing the situation.

c) All road construction projects should comply with the newly developed building and construction legislations and must conform to existing global best practices that ensure sustainability of engineered infrastructures.

d) Drainage systems across Kebbi state should be regularly de-silted, inspected and monitored to take note of any failure with a view of effecting repairs.

e) Concerted efforts must be geared towards provision of adequate master plan, updated city planning maps, policy implementation and the integration of environmental planning to urban development.

\section{Acknowledgement}

The authors wish to acknowledge the Tertiary Education Trust Fund (TETFUND) for graciously sponsoring this study under the 2016/2017 Internally Based Research (IBR) scheme.

\section{References:}

1. ActionAid (2006). Climate change, urban flooding and the rights of the urban poor in Africa: Key findings from six African cities, London, Action Aid International.

2. Adedeji, O. H., Odufuwa, B. O., and Adebayo, O. H. (2013). Building Capabilities for Flood Disaster and Hazard Preparedness and Risk Reduction in Nigeria: Need for Spatial Planning and Land Management, Journal of Sustainable Development in Africa, 14(1), 4558.

3. Adegbola, A. A., and Jolayemi, J. K. (2012). Historical rainfall-runoff modeling of river Ogunpa, Ibadan, Nigeria,Indian Journal of Science and Technology5 (1), 2725-2728.

4. Agbonkhese, O., Yisa, G. L and Daudu, I. (2013). Bad Drainage and its Effects on Road Pavement Conditions in Nigeria,Journal of Science and Technology, 3(10). 
5. Bakari, A. (2014). Hydrochemical assessment of groundwater quality in the Chad Basin around Maiduguri, Nigeria,Journal of Geology and Mining Research,6(1), 1-12.

6. Baldassarre, M., Kooy, J. S., and Kemerink, L. (2013). Towards understanding the dynamic behavior of floodplains as human-water systems, Hydrol.Earth Syst. Sci.17(8), 3235-3244.

7. Bashir,O., Oludare, H., Johnson, O., and Aloysius, B. (2012). Floods of fury in Nigerian cities,Journal of Sustainable Development,5(7),6979.

8. Bates, B. C., Kindzewicz, Z. W. (2018). Climate Change and Water. Technical paper of the Inter-governmental Panel on Climate Change, IPCC Secretariat, Geneva.

9. BatesHorritt, P. D., Smith, M. S. and Mason, C. N. D. (1997). Integrating Remote Sensing observations of flood inundation likelihood,Hydrol. Process 11(14), 1777-1795.

10. Bello, M. N., and Jeb, D. N. (2014). Analysis of flood risk inundation hazard in Birnin Kebbi town, Kebbi state, Nigeria,International Journal of Geomatics and Geosciences, 5(1), 119-131.

11. Pradhan, B. (2009). Flood susceptible mapping and risk area delineation using logistic regression, GIS and remote sensing, Journal of Spatial Hydrology,9(2), 1- 18.

12. Chokor, B. A. (2003). Government Policy and Environmental Protection in Developing World, Environmental Management, 17(1), 15-30.

13. Dutta, D. J., Teng, J., Vaze, J., LeratHughes, J.S. (2013). Storagedbased Approaches to Build Floodplain Inundation Modelling Capability in River System Models for Water Resources Planning and Accounting, J. Hydrol. 504(0), 12-28.

14. Grelot, F., Barreteau, O. (2012). simulation of resilience of an insurance System to Flood Risk,International Environmental Modelling and Software Society International Congress, Pathways and visions under uncertainty, sixth Biennial meeting, Leipzig, Germany.

15. Gwary, D. (2008) Climate change, food security and Nigeria Agriculture, Paper presented at the workshop on the challenges of climate change for Nigeria. NISER19th-20th May, 2008.

16. Kolawole, O. M. A., Olayemi B., and Ajayi, K. T. (2011). Managing Flood in Nigerian Cities: Risk Analysis and Adaptation Options-Ilorin as a Case Study, Scholars Research Library, 3(1), 17-24.

17. Merz, B., Vorogushyn, S., and Lall, U. (2015). Charting unknown water-on the role of surprise in flood risk assessment and management, Water Resour. Res.51(2), 6399-6416. 
18. Van der Most, H., and Marchand, M. (2017). Selecting Measures and Designing Strategies for Integrated Flood Management, a Guidance Document, World Meteorological Organization.

19. Nelson, S. (2001). River systems and causes of flooding, Geology 204 lecture notes, Tulane University, Retrieved October 23.

20. Olajuyigbe, A., Nwafor, J. C., and Akan, T. (2012). Environmental Impact Assessment for Sustainable Development: The Nigerian Perspective, Enugu EL DEMAK Publications.

21. Pinto, J. G. and others. (2013). Identification and ranking of extraordinary rainfall events over Northwest Italy: the role of Atlantic moisture, Journal of Geophysical Research - Atmospheres.

22. Sada, P., and Odemerho, F. (1988). Environmental issues and management in Nigeria development, Evans publishing, Ibadan.

23. Samuel, R. and others. (2015). Social vulnerability to floods: review of case studies and implications for measurement,International Journal of Disaster Risk Reduction, 14(4).

24. UN (2019). Flood Risks in Cities: Global Review of Flood Impacts on Cities.

25. UNISDR (2019). Words into Action Guidelines: National Disaster Risk Assessment Hazard Specific Risk Assessment Report.

26. Wizor, A., and Week, C. W. (2009). Mapping Flood Vulnerable Areas in a Developing Africa, Journal of Sustainable Development in Africa, 11(4), 180-194.

27. World Bank (2017). Developing Early Warning Systems: A Checklist' 2, http://www.unisdr.org/files/608_10340.pdf accessed 6 July 2018. 